\title{
Cinderella in Babylon: the representation of housekeeping and housekeepers in the UK television series Hotel Babylon
}

\section{ABSTRACT}

This article examines representations of housekeeping and housekeepers in the popular television series Hotel Babylon. We take a reflective approach in considering how identities and roles in the Hotel Babylon series are constructed, regarding the housekeeping department and its workers. We identify that the representation of housekeeping work and employees is one of mainly sexualized victims, migrant workers and denigrated employees. Some possible effects of the identity and role constructed in this series are discussed; in particular an undermining and undervaluing of a career in housekeeping. This study suggests more fundamental concerns about sustaining service quality and employment relationships in the hotel sector.

\section{KEYWORDS}

Hotel Babylon housekeeping representation migrants sexualization 


\section{INTRODUCTION}

Television is an important, although understudied, medium through which to examine hospitality work. Television programmes set in hospitality contexts, such as 'Allo 'Allo! (BBC1 1982-1991) and Fawlty Towers (BBC2 1975), have long captured the imagination of television audiences and often using humour, provide ideal contexts in which to profile hospitality work. Television programmes based on hospitality typically feature gendered workscapes, with strong themes of class and ethnicity. In this article we focus on the contemporary television series Hotel Babylon, exploring the dialectic between the hidden/invisible work of housekeeping and the public/visible nature of television. We investigate how the interplay of race, class, gender and citizenship is represented in Hotel Babylon. We also note that Hotel Babylon serves as an excellent medium through which to examine the current geopolitical situation regarding undocumented migrant labour.

'In many ways hotels are synonymous with sex, romance and adventure linked in popular culture with clandestine meetings of spies and lovers, with wedding nights, honeymoons and illicit or transitory sexual assignations' (Pritchard and Morgan 2006: 765). Recent contributions on the interaction between work and tourism have, however, challenged traditional notions of travel as out-of-the-ordinary indulgent experiences (Uriely and Reichel 2000). Also, for many, hotels are a workplace.

High employee turnover within the hospitality industry has been accepted as the norm, creating a 'turnover culture' (Deery 2002) in which management and employees show acceptance of turnover behaviour. For example, figures released in New Zealand in 2008 show the hospitality sector suffering a labour turnover rate of $25.8 \%$ (Statistics New Zealand 2008). Hospitality turnover is almost double that of comparison sectors - Manufacturing, $11.7 \%$ and Retail, 15\%. Unofficial figures from the New Zealand Hotel Council put turnover rates in the hotel sector at almost 50\%. A 2009 survey by the UK Chartered Institute of Personnel and Development (CIPD) also highlighted hospitality as one of the highest turnover segments of the private sector (CIPD 2009). This high turnover can be partly attributed to the low wages paid and the industry being characterized by historical practices based on stereotypes and myths (e.g. 'You work in hospitality until you get a real job').

This article examines representations of both housekeeping and housekeepers in the popular television series Hotel Babylon, a contemporary television programme portraying the purportedly real life and inner workings of a five-star hotel in London and its workers.

Bad behaviour, you would think, is par for the course in the luxury hotel business: a demanding guest here, a drunken guest there, an illicit couple, some broken glasses. But what the hotel staff really has to put up with from guests [...] would shock even the most jaded of souls. And it is usually the chambermaids who are at the sharp end.

(BBC 2006: 1)

We posit that Hotel Babylon represents hotel housekeeping as a hot bed of migrant workers, sexual activity and denigration - serving to construct the image of a hospitality career in housekeeping as undesirable to many. Given that for many people, including potential employees, this may be their only exposure to five-star hotels we suggest that these representations are 
powerful. These representations may undermine staff retention efforts in 'real' hospitality workplaces, as well as reinforce hierarchies in hotels based on gender, class, race, ethnicity and citizenship.

We structure the article as follows. First, the literature on television and hospitality career impressions is discussed. Second, there is a review of literature on hotel housekeeping. Third, the approach taken in this article is overviewed. Fourth, findings are presented and discussed, focusing on three themes that emerged from our analysis. Then, we note the potential effects of representations such as these on the housekeeping sector of the hotel industry, followed by conclusions.

\section{TELEVISION AND HOSPITALITY CAREER IMPRESSIONS}

While various authors have examined the subject of film-induced tourism, specifically through the lens of film images and destination marketing (Beeton 2001; Frost 2006), comparatively less scholarly attention has been devoted to television and hospitality. While film and television dramas are widely recognized as a stimulus that can induce people to visit destinations $\left(\mathrm{O}^{\prime} \mathrm{Connor}\right.$ et al. 2009), less is known about how they act in positive and negative ways on perceptions of tourism and hospitality work and even potential career choices in these industries.

Lynch (2005) states that researchers could usefully explore host and guest relationships, within the hospitality setting, through a wider range of mediums, such as 'gestalt analysis of drawings, poetry, literature, the moving image, or art' (Lynch 2005: 545). We argue that television can serve as an excellent mirror through which to view hospitality and wider society. As Parks and Kumar (2003: 3) note, 'we are all shaped in one way or another by the social, economic, and cultural relations that the medium of television has historically worked to structure and reproduce'. Television programmes set in hospitality contexts such as 'Allo 'Allo! and Fawlty Towers have proved extremely popular with television audiences. In 2000, Fawlty Towers was voted the UK television industry's all-time favourite British television programme (Fawltysite.net 2010). 'Allo 'Allo! ran on BBC TV from 1982 to 1991, achieving ratings of over 11 million (BBC Worldwide 2002).

Television depicts numerous workplaces, showing people engaged in various work-related activities. It serves many functions, 'including providing outlets for mood control, models of emulation, and scripts for exploring possible selves' (Rivadeneyra and Ward 2005: 453). Although television is an important source of information about the environment of work, few have analysed television's depiction of occupational roles, particularly in relation to gender and racial stereotypes (Signorielli and Kahlenberg 2001). Hospitality on television has been examined by researchers such as Bartley (2007) who investigated how ideological notions of Britishness is applied within the textual narrative of Fawlty Towers and Randall (2000: 130) who examined television food personalities and found that such programmes can produce complex and potentially powerful influences on the concept of hospitality 'that involve social attitudes, social relations and consumer motivations'.

Television can introduce viewers to occupations they may not have previously considered (Hoffner et al. 2008), thus serving as an important and easily accessible medium for people to access career information. However, 'television viewing is associated with beliefs about the job activities involved in specific occupations, and with a tendency to believe that occupations on 
1. Exceptions may, however, exist in properties that host gaming facilities where the majority of revenue comes from these activities. television have more glamour and higher income, but require less effort ${ }^{\prime}$ (Hoffner et al. 2008: 285).

In a television series the viewer's relationship with the story and characters is developed over time. Audiences can view television programmes as extensions of their own lives ( $\mathrm{O}^{\prime}$ Connor et al. 2009). The television serial stimulates personal involvement by viewers as, according to Piemme (1975 cited in Ang 1991), to watch a serial is also to involve oneself in it. In serial television, the 'lifelike acting style ensures that the distance between the actor and the character is minimalized so that the illusion is created that we are dealing with a "real person"' (Ang 1991: 30). Individual characters can have a strong effect on viewers' beliefs, as connections to characters produce an experience of mediated closeness, which facilitates the persuasive effects of the message (Bilandzic 2006). Studies have found that viewers want to be like characters they perceive as attractive and successful (e.g. Hoffner et al. 2008; Hoffner and Buchanan 2005; Reeves and Greenberg 1977).

\section{HOUSEKEEPERS AND HOUSEKEEPING IN THE LITERATURE}

Feminist research on the service economy has shown how gender and sexuality are embedded in the organizational structure of work, informing the conceptualization of jobs, job specifications, control over workers, and relations between women and men (Cabezas 2006). Veijoa (2009) explains that in the numerous 'old jobs' in tourism for women, from maids and prostitutes to stewardesses, gender is a fixed identity - a female body (see, for example, Sinclair 1997; Ehrenreich and Hochschild 2003; Veijola and Valtonen 2007) and that domestic arrangements between the sexes in the tourism industry leads to an inherently gendered workscape. "Old work" of industrial forms and hierarchies of work still characterizes employment in tourism globally, featuring the predominance of low-skilled jobs, the appropriation of migrant labour, high employee turnover, unsocial working hours and lack of trade union presence' (Veijola 2009: 116). The largest proportions of women workers are found in the 'dirtiest' and most operational hotel jobs, those requiring domestic skills for which women are perceived as inherently skilled (Kinnaird et al. 1994; Adib and Guerrier 2003).

As the majority of hotels are 'accommodation led', with most revenue derived from the sale of rooms (Hunter Powell and Watson 2006), housekeeping is arguably the most important department in hotels. ${ }^{1}$ It would therefore be reasonable to expect housekeepers to be recognized as a key part of hotel operations. However, housekeeping work is often stigmatized because of its association with personal servitude (Ashforth and Kreiner 1999). Housekeepers undertake tasks that Hughes (1971) terms 'dirty work', thus symbolizing a lack of dignity and status and potential degradation of the worker.

Scherzer et al. (2005: 1) note that housekeeping is 'characterized by a predominantly female workforce, repetitive physical tasks, low job control, low wages, increasing use of contingent employment, and few opportunities for career advancement'. Wood (1994) adds to this viewpoint, noting it is conventional to regard cleaning work as 'unskilled', despite the fact that such work requires 'a complex balance of task organisation, the application of (though low-level) technology and technological processes and the knowledge of these processes' (Wood 1994: 62). Harris (2009), through her analysis of the 35-year career of an executive hotel housekeeper, found real 
and symbolic consequences of a positive, collectivist workplace culture in hotel housekeeping. Housekeeping is gendered work (Scherzer et al. 2005). Traditionally women are employed in roles that are considered representative of their domestic roles, using the same skills base (Kinnaird et al. 1994). According to Wood (1994), cleaning work in the home has been viewed as a wife's duty, a view that has arguably been transferred to the public performance of cleaning in paid employment. 'Chambermaids rank amongst the lowest of the low in hotel work, treated as a cheap and easily replaceable resource by employers and often spurned by their fellow employees' (Wood 1992: 78). Housekeeping, however, while commonly thought of as menial, requires a considerable amount of attention to detail and speed in order to ensure that all tasks are performed in a short space of time (Ryan 1998).

Although it is usual for room cleaning to take place when guests are not in the room, occasionally a guest may be present before the room has been completed, resulting in the housekeeper being alone with a guest in a room. This is a potential concern as, as noted by Hunter Powell and Watson (2006), the behaviour of some hotel guests may be affected by their freedom from the constraints of home.

Housekeeping is often considered an entry level position which attracts immigrant workers - often with English as a second language. Amanda Cooper (spokesperson for the UNITE HERE labour union in the United States of America) notes that hotel housekeeping is dominated by immigrants (Erpenbach 2006). Hunter Powell and Watson (2006) also observe that housekeeping operations in major UK cities are often dominated by migrant and ethnic minority groups. Lucas (1995) posits that ethnic minority and migrant workers are clustered in the lowest graded work in the hospitality industry and that it is common to find that the workers in hotels are drawn from the same ethnic minority or migrant groups - particularly in the 'ghetto of housekeeping'. Such work, however, may not constitute their 'career of choice' but rather offers them a way to gain employment. Hotel housekeeping in the United Kingdom is often contracted out, drawing a labour pool from agency staff (Lai and Baum 2005). Agencies specializing in the provision of contract hospitality and cleaning staff can be an easier entry point into the workforce for migrant workers than finding a full-time position.

Based on this body of literature which studies housekeepers and housekeeping in the everyday or lived experience, we seek to analyse how housekeepers and housekeeping are represented in a sector of popular culture - based on the television series Hotel Babylon.

\section{RESEARCH CONTEXT, APPROACH AND METHOD}

We examine knowledge constructed within the television series Hotel Babylon, and consider the potential effects of that knowledge. To do so, we consider representations of housekeeping and housekeepers in the eight episodes of Series 1 . Here, we outline the research context and analytical method.

\section{Research context}

We used the eight episodes of Series 1 of the television series Hotel Babylon (2006) as the site for analysis for this study investigating representations of housekeeping and housekeepers in popular culture. We selected Hotel Babylon as it is one of the few television shows that feature the hotel sector and housekeepers. It was also chosen due to its high profile and international presence. 
Hotel Babylon is a scripted drama that often has a prime timeslot and runs for an hour each week (including advertisements). It achieves high ratings, with around five million viewers each episode in the United Kingdom. To date it has aired in over 23 countries. Hotel Babylon chronicles some of the most outlandish and downright appalling aspects of life behind the bevelled doors of British society's best hotels (Common Sense Media 2008). The series itself is based on the same-named novel by Imogen Edwards-Jones, who also authored the books Air Babylon, Beach Babylon and Fashion Babylon. Hotel Babylon is described on the BBC website as follows.

Inspired by Imogen Edwards-Jones's searing exposé of life in London's luxury hotel industry, Hotel Babylon takes viewers on a journey beyond the glamour and façade of the smiling faces and glittering chandeliers and into the frenetic, non-stop world of the staff. Hotel Babylon is not based on any one particular real hotel. It evolved as an amalgam of three or four very different hotels.

(BBC 2008)

Harper (2008: 115) notes that while 'Hotel Babylon has attracted much journalistic opprobrium for its concern with celebrity and is often dismissed' it is hugely popular. Audience numbers for the first screening of Season 1 were around five million, and increased during the second season (Broadcasters' Audience Research Board 2007) - suggesting that Hotel Babylon merits serious critical attention.

In today's television culture we, as do others (e.g. Hoffner et al. 2008; Simanoff 2006), suggest television programmes are a source of knowledge and influence. In relation to knowledge about five-star hotels, hotels and hotel work more generally, we view Hotel Babylon as an important research site. Harper (2008: 113) identifies that luxury hotels, rather than being extraordinary, are 'places where everyday social antagonisms are brought into unusually sharp focus'. We suggest that for many, including potential employees, popular culture, predominantly television, may be their only exposure to fivestar hotels and five-star hotel work. As such, Hotel Babylon, a series that has high viewing rates, has potential effects on the construction of the hotel workplace and hotel work. We therefore analyse representations of housekeeping and housekeepers within this context and seek to identify potential effects.

\section{Character descriptions}

Like many television programmes, Hotel Babylon is character focused. It uses several popular British actors rather than actual hotel employees. While, in our analysis, we considered the representation of housekeepers and housekeeping work in general (i.e. considering both named characters and unnamed characters), many of the storylines in relation to housekeepers and housekeeping involve the main characters of the show. As such, we provide, in Table 1, a brief description of the major characters from Series 1, as presented in the BBC's own marketing information.

\section{Analytical method}

Hall (1997) identifies three approaches to explaining how representation of meaning through language works - the reflective, the intentional and the constructionist or constructivist approaches. He notes that each approach 


\begin{tabular}{ll}
\hline $\begin{array}{l}\text { Jackie (Head of } \\
\text { Housekeeping) }\end{array}$ & $\begin{array}{l}\text { Fiercely protective of her team - but sometimes finds herself in deep trouble } \\
\text { as a result. }\end{array}$ \\
\hline $\begin{array}{l}\text { Rebecca (General } \\
\text { Manager) }\end{array}$ & Likes to control a tight ship as GM. Does not take nonsense from staff. \\
\hline $\begin{array}{l}\text { Charlie (Deputy } \\
\text { General Manager) }\end{array}$ & $\begin{array}{l}\text { A jack of all trades, Charlie introduces us to the world of the hotel - exposing } \\
\text { the dirty little secrets. }\end{array}$ \\
\hline Tony (Concierge) & He can get his guests anything within 24 hours. An effortless charmer. \\
\hline $\begin{array}{l}\text { Anna (Head } \\
\text { Receptionist) }\end{array}$ & $\begin{array}{l}\text { Anna is, let us say, aspirational and gorgeous. As far as she is concerned it is } \\
\text { only a matter of time before she bags a wealthy man. }\end{array}$ \\
\hline $\begin{array}{l}\text { Gino (Head } \\
\text { Barman) }\end{array}$ & $\begin{array}{l}\text { Half-Italian, half-Spanish, Gino is proud of his dual identity. His background } \\
\text { might be slightly chequered, but he is undeniably clean and kind hearted. }\end{array}$ \\
\hline Ben (Receptionist) & \begin{tabular}{l} 
Ben loves the luxury hotel world because of its style and inherent 'campness'. \\
\hline James (F\&B
\end{tabular} \\
$\begin{array}{l}\text { He is extremely pretentious and old school. He just cannot help looking } \\
\text { down his nose at people who cannot pronounce foreign labels properly. }\end{array}$ \\
\hline
\end{tabular}

(Adapted from BBC 2008)

Table 1: Series 1 character descriptions.

addresses the questions, 'Where do meanings come from?' and 'How can we tell the "true" meaning of a word or image?'

In the reflective approach, language functions as a mirror through which the inherent meaning of an object, person or idea is reflected. According to this approach, 'true' meaning exists in the world and language functions 'like a mirror' (Hall 1997: 24). In the intentional approach 'words mean what the author intends them to mean' (Hall 1997: 25). Language is therefore private, as the speaker/author imposes his/her own unique meaning on the world. The third approach, the constructionist approach, recognizes the public and social character of language. As such, 'it acknowledges that neither things in themselves, nor the individual users of language can fix meaning in language' (Hall 1997: 25).

We take a constructionist approach to meaning in language. We are interested in how representational systems construct and communicate meaning (whilst recognizing that, as authors/researchers, we too are involved in the construction). In considering representations we take a particular view of language and use the term in a broad and inclusive way.

Any sound, word, image or object which functions as a sign, and is organized with other signs into a system which is capable of carrying and expressing meaning is, from this point of view, 'a language'.

(Hall 1997: 19)

As such, we consider sounds, words, images and objects that work to represent subjects (housekeepers) and job roles (housekeeping). How we conducted the analysis is now outlined.

The method of inductive thematic analysis (Warren and Karner 2005; Pehlke et al. 2009) was used to determine the key messages about 
2. Due to space constraints we are unable to include full details of this analysis here. For a document containing brief episode descriptions and tables outlining scenes and references to or about housekeepers or housekeeping in each of the episodes, please contact the authors. housekeepers and housekeeping work in the episodes. The initial stage of data collection and analysis involved two of the researchers watching separately all eight episodes of Hotel Babylon, Series 1. We used an approach of investigator triangulation as a validity procedure. Triangulation is a systematic process of sorting through the data to find common themes or categories by eliminating overlapping areas (Creswell and Miller 2000). An advantage of investigator triangulation is that confirmation of data among investigators lends greater credibility to the observations (Denzin 1970). The initial viewing of the episodes was to familiarize the researchers with the show and its content and characters. In the second closer viewing of each episode, one researcher recorded each time housekeeping staff were featured or the staff or activities of housekeeping were mentioned noting the time, length and scene description. These notes (close to nine pages) were then checked for accuracy by the second researcher familiar with the series. Once notes were complete, the two researchers came together to conduct inductive thematic analysis by identifying common portrayals or themes from the episodes through an analysis and discussion of the scene descriptions. Three themes that reflect the way housekeepers and housekeeping are portrayed were decided upon: sexualization and sensuality; the use (and abuse) of illegal migrant staff; and denigration of housekeepers and housekeeping work. These themes, and the labels that were assigned to each, were perceived by the researchers as most accurately depicting representations of housekeeping and housekeepers in the series. Through comparing these representations to the extant literature on housekeepers and housekeeping, along with considering these representations alongside those of other characters in the series, we also noted silences and absences. ${ }^{2}$ Findings from this analysis are presented and discussed now.

\section{FINDINGS}

Findings are presented in three parts. First, we note the representations of housekeepers and housekeeping in general, that is, we note their presence (and absence) within the eight episodes. Second, we present and examine themes emerging from our analysis of the episodes. Third, we identify potential effects of these representations in the discussion that follows.

\section{Representations of housekeepers and housekeeping}

Three themes dominate the eight episodes analysed: sexualization and sensuality; the use (and abuse) of illegal migrant staff; and the denigration of housekeepers and housekeeping work. These themes intersect with each other. These themes are consistent with those noted in other studies of housekeeping (Biswas and Cassell 1996; Hunter Powell and Watson 2006) and more generally in tourism employment (Purcell 1996).

Through a discussion of the three themes, we argue below that housekeepers and housekeeping, within the episodes analysed, are represented as being at the lowest end of the hotel hierarchy. The prevailing discourse of drudge work, often performed by the lowest end of the labour force (illegal migrant workers), is (re)produced in this fictionalized story. Although many other hotel departments portrayed in the series appear overtly glamorized (e.g. reception and bar), housekeeping is represented in a manner similar to what is identified by previous researchers discussed above who have investigated the hotel housekeeping workplaces. 


\begin{tabular}{lccc}
\hline Episode & $\begin{array}{c}\text { Number of scenes } \\
\text { featuring housekeepers }\end{array}$ & $\begin{array}{c}\text { Number of scenes referring to } \\
\text { housekeepers }\end{array}$ & Total time \\
\hline 1 & 16 & 5 & 13 minutes 4 seconds \\
\hline 2 & 25 & 5 & 12 minutes 45 seconds \\
\hline 3 & 22 & 2 & 6 minutes 50 seconds \\
\hline 4 & 14 & 3 & 11 minutes 29 seconds \\
\hline 5 & 18 & 3 & 25 minutes 50 seconds \\
\hline 6 & 4 & 0 & 2 minutes 54 seconds \\
\hline 7 & 24 & 1 & 12 minutes 32 seconds \\
\hline 8 & 25 & 4 & 12 minutes 16 seconds \\
\hline
\end{tabular}

Table 2: Number of scenes featuring or referring to housekeepers or housekeeping.

Housekeepers and/or housekeeping work feature to varying degrees in all eight episodes. Apart from Episode 1, which centres around the character of Head Housekeeper Jackie and her sexual liaisons with Charlie, Episodes 2 and 5 feature housekeeping and housekeepers most prominently. Episode 2 sees the return of a former hotel housekeeper as a guest, which results in discussions about the role of the housekeeper, and Episode 5's major plotline is a raid on the hotel by immigration officers involving characters from housekeeping. Episode 6 has the least presence of housekeepers or housekeeping work with only four scenes - all featuring Head Housekeeper Jackie.

\section{Sexualization and sensuality}

Throughout the episodes analysed a strong theme of sexualization and sensuality was present. This theme was evident in the way in which the head housekeeper was characterized, the positions and locations the housekeeping staff were filmed in, and perhaps most explicitly in the innuendos made by other staff and the programme's narrator. At odds with common portrayals of head housekeepers is the construction of the character of Jackie, who is an attractive and sensual 27-year-old. Head housekeepers often have considerable experience and are not normally this young. Like many of her staff, Jackie is an illegal migrant, residing in the United Kingdom with an expired visa. Unlike most of her staff, however, she is from a western nation (Australia), not eastern Europe or Africa. Within the episodes, Jackie is clearly distinguished from her staff by dressing in power suits and possessing a perfect command of the English language, with only a hint of an accent (albeit from a western nation). These characteristics make her desirable to Charlie, the English deputy general manager. As head housekeeper, Jackie has access to a range of areas of the hotel - which makes it easy for her and Charlie to have frequent sexual liaisons. Jackie is often the one who is waiting for him to arrive, and the one who remains to clean up afterwards. After all, it is her role to maintain high room standards! Such scenes construct a relationship between bodies, hospitality and cleanliness, in which Charlie has the power and Jackie is clearly 
assigned a service role. These themes reinforce the finding that housekeepers labour in place-based forms of 'body-work' (Wolkowitz 2006) that depend on co-presence and performance of physical work, directly or indirectly, on the bodies (which includes fluids and wastes) of others as well as in typical feminized parts of routinized service sector work (McDowell 2008).

The sexualization of the housekeeping staff in general is largely isolated to the sexualization of Jackie as a sexual object. This sexualization starts in Episode 1 where there is a scene filmed from the back showing Jackie bending over while stacking towels. This episode also features several scenes with Jackie and Charlie overtly flirting with each other at various places in the hotel, especially while the two of them are conducting room inspections. Nearly 40 minutes into Episode 1 they have sex, after which Charlie describes it as a 'weird situation'. The sexualization of Jackie continues in Episode 2, as does the flirting between Jackie and Charlie. In Episode 3, Head Barman Gino states that he would like a lap dance from Jackie, further sexualizing her character.

In a scene at the beginning of Episode 4, Jackie is left waiting for 25 minutes in a hotel room for Charlie to join her. When he finally arrives he starts undressing stating: 'The sooner we start - the sooner we finish.' Jackie is clearly not impressed and asks him how he defines a relationship. He replies by asking her if she has a spare button noticing he has lost one from his shirt. This episode does not end the sexualization of Jackie. An example of the way she continues to be portrayed can be clearly seen in Episode 8 when a bellboy enters a room that Jackie and Charlie have rented for the night. Jackie is in bed undressed and asleep and the bellboy clearly looks her over.

\section{The use (and abuse) of illegal migrant staff}

Another strong theme to evolve is the use (and abuse) of illegal migrant staff. This theme is characterized in many references made to the ethnic diversity of staff, the illegal status of many of them in terms of work and residency, their attraction as cheap labour and their accents and problems with the English language, which makes communication problematic. The most obvious depiction of power relations between the hotel and illegal migrant housekeeping staff of various ethnicities can be seen in Episode 5, where, in the first minute, Charlie says:

The most important people in the hotel are the cooks and cleaners, but you will never see them, they are our dirty little secret, forbidden from even entering the same breathing space as any of guests. Many are here illegally - they don't even exist. But we are happy to turn a blind eye to fake papers and dodgy passports. If you have two hands to clean with and two knees to crouch on then who cares whether you should be here or not. We feed and water them, and the questions we don't ask are the ones they don't want to answer. Besides, if it weren't for them we would have to employ regular people with national insurance contributions, minimum wages and tides of complaints about working conditions, and well, are you willing pay for that? This is the way it has always been. Besides who really built the pyramids - the pharaohs or the slaves?

While in the other seven episodes several negative references are made to housekeeping staff, such as management's wish for them to 'speak in English', 
and the portrayal of opportunism and dishonesty amongst housekeeping staff, Episode 5 is the most overt demonstration of the distain that illegal migrants are held in. Conversely, it also shows how much the industry depends on this labour to keep the hotel operational.

In Episode 5 immigration officials raid the hotel. Being the main storyline of the episode, it features the most reference to, and images of, housekeepers and housekeeping of all the episodes analysed. To warn of a raid by immigration, the hotel has a password warning system where, once activated, illegal staff are hidden in a small room. Jackie, upon learning that a male staff member is hitting his daughter who is working in the housekeeping department, arranges for him to be the sacrificial lamb given up to immigration. Jackie does this in order to protect herself once an immigration official learns of her own expired visa status. Giving him up in this way means he will be deported back to Sierra Leone, where he worked as a doctor and was arrested. The storyline makes it clear that returning means he will probably face death.

The contrast between housekeepers and housekeeping work being essential (as seen in Charlie's comment above), and as illegal migrants to be 'hidden away', has an overall effect on the construction of housekeeping staff and their role within hotels. Furthermore, this notion that housekeepers should be 'hidden away' is not only evident when immigration comes calling but in general. This is discussed further now.

\section{Denigration of housekeepers and housekeeping work}

Our analysis of the episodes found several scenes featuring the denigration of housekeepers and housekeeping work. The portrayal of housekeepers and their work by the programme's writers and producers reproduces a broader cultural stereotype of hotel housekeeping work, rather than demonstrating actual lived experiences or attitudes of cleaning staff. Beyond the sexualization of the staff, particularly Jackie, and the use of illegal migrant labour, the denigration of housekeepers continues in other ways in Series 1. For example, less than ten minutes into Episode 1, at a hotel department heads meeting, one manager casually accuses housekeepers of stealing. Others present at the meeting passively agree by not challenging this claim.

Furthermore, housekeeping staff appear to be easily manipulated by management and other staff, particularly if the housekeeping staff can profit monetarily from agreeing to odd requests. This representation begins in Episode 1 when a housekeeper is paid by Tony, the concierge, to scream at a famous band who are staying at the hotel, to show the band how desirable they are. The characterization of housekeeping staff as willing profiteers from different situations continues in Episodes 4 and 8. In Episode 4, Head Receptionist Anna spends the night with a guest hoping for a relationship. Instead he leaves 500 pounds next to the bed apparently interpreting their liaison in quite a different way. Albeit hurt, ever the opportunist, Anna takes the money. When Charlie learns of this, he is angry and arranges for the money to be returned courtesy of a housekeeper whom he convinces to tell the guest that she took the money thinking it was a tip for servicing the room. Charlie pays the housekeeper 30 pounds for agreeing to lie to the guest and take the blame due to her 'stupidity'. In Episode 8 a housekeeper does a deal with General Manager Rebecca - her silence about uncovering that Rebecca has been staying at the hotel in exchange for shifts in the restaurant (restaurant work is clearly represented as a move up from housekeeping). 
Unprofessional and poor work practices of housekeeping staff are also inferred in Episodes 1 and 7. In Episode 1, Charlie, after having sex with Jackie, goes to use a glass in the hotel room. Jackie however stops him by sharing that her staff do 'disgusting things with drinking glasses and towels', at which time a scene is shown of a housekeeper cleaning the toilet and glasses with the same towel. While this scene could be interpreted as a case of the staff gaining a small victory against the hotel and the guests they are required to serve, it also portrays unprofessional behaviour and thus denigrates the work of housekeepers and their attitudes towards hygiene. In Episode 7, when housekeepers get called upon to locate a missing guest in the hotel, various scenes depict housekeepers performing their job. One housekeeper is shown relaxing on one of the beds eating chocolate and reading a magazine.

Violence is another feature identified within the theme of denigration. Episode 1 features a housekeeper who was beaten up by a guest high on cocaine. After the incident General Manager (GM) Rebecca first asks if the fixtures in the room were damaged before turning to the staff member to enquire about her welfare. Furthermore, when the maid speaks with a heavy accent the GM barks at her to 'speak English'. To placate the maid after the assault the GM instructs Charlie pay her an extra 50 pounds. Charlie says 50 pounds is not much for the GM to be able to 'shit on your own staff'. Upon hearing about these events Jackie takes on the GM stating that no one attacks her staff! The GM replies that 'a chambermaid will tell you anything for a price of a stamp'. At the end of the episode Charlie chastises the guest who assaulted the housekeeper asking how dare she beat up a woman who 'cleans up your shit for minimum wage'.

In Episode 2, staff rally to help an elderly ex-housekeeper celebrate her fiftieth wedding anniversary. During her stay she is treated like a celebrity guest. She explains to the managers that when she was working at the hotel 'chambermaids used to be instructed not to make eye contact with guests'. Later in the episode the lady dies, and while the staff plan to take her body out by the service elevator, the GM announces that she will be taken out the front entrance, just like any other guest would. It also implies that if she were still a housekeeper then being taken out via the service elevator would be fine. This scene is the only scene where housekeeping staff (other than Jackie) can be seen in the lobby or front-of-house area, with many scenes occurring in the dark corridors, not visible to guests or in the hotel hallways.

Housekeepers and housekeeping (excluding references to Jackie) are largely absent from several of the episodes, in particular Episode 6 where there are no scenes of housekeepers or housekeeping other than those featuring Jackie. In scenes that do feature housekeepers or housekeeping work throughout the series, the theme of denigration continues to be seen. Examples include a complaint made by a guest about room standards (Episode 3); reference to a housekeeper having to clean out the bath filled by a purging model (Episode 3); and Jackie involved in the bribing of an auditor so as to ensure inconsistencies in housekeeping supplies are not noticed - once again implying theft (Episode 7).

\section{DISCUSSION}

This analysis of Hotel Babylon has uncovered possible underpinning representations and power relations, which we argue could potentially impact on constructions of housekeepers and housekeeping more broadly. While 
Imogen Edwards-Jones, and subsequently the series' writers, producers and directors, have constructed a fictional site called Hotel Babylon, the plotlines were constructed from stories told to her by an anonymous manager of a five-star London hotel, plus Edwards-Jones's own investigations:

My year on the frontline of the ultimate service industry was a real education. I never expected such decadence and debauchery, I never expected such seediness or such depravity. The highs and the lows, the human sadness contrast amazingly with the great beauty and the fantastic Epicurean excellence they achieve. The capital's luxury hotels are extraordinary places, full of extraordinary stories and are a microcosm of the world outside.

(Edwards-Jones and Anon 2004)

Discourses of sexual encounters and sensuality both frequently frame the marketing of contemporary hotels and tourist resorts, often implying the promise of risk, novelty and excitement, often in exoticized and occasionally eroticized language (Pritchard and Morgan 2006). As the findings above illustrate, themes of sex and sensuality are very much portrayed as the norm in Hotel Babylon amongst guest-guest relations, guest-staff relations and, in particular, staff-staff relations. The end result is the portrayal of a very sexualized workplace. Furthermore, the accepted sexuality to be played with is heterosexuality while homosexuality forms the basis of anguish and comedy (e.g. in Episode 5 Gino the barman pretends to be gay for extra tips). According to Pritchard and Morgan (2006), cultural and feminist geographers have argued for some time that there are no politically neutral spaces, and much work has focused on the ways in which places are heterosexualized (e.g. Aitchison 1999; Duncan 1996). Yet there is little of this cultural or feminist influence in hospitality studies. Indeed, Darke and Guerney (2000) have drawn attention to the 'curious' absence of a broad feminist perspective on hospitality, particularly given the fact that so many employee-guest interactions are overlain by social relations of gender.

Hotel staff members are vulnerable to harassment because of their status relative to the customers (Guerrier and Adib 2000). The kinds of kinesic cues which management encourage employees to display, in order to show warmth towards hotel customers - smiling, frequent eye contact, open body posture, leaning forward - are not only associated with friendliness and courtesy but also with intimacy and sexual attraction (Burgoon et al. 1990). These behaviours are typically found more in customer facing roles such as reception and restaurant service. However, in Hotel Babylon it is the housekeeping staff, particularly the head housekeeper, who are overtly aligned with sexual attraction. Shots of housekeeping staff making beds, bending over to clean fixtures, sashaying down corridors with trolleys, predominantly without giving them a voice, are designed to show them as willing to serve, with a hint of double meaning, as they are largely shot in bedrooms. Ehrenreich (2002), based on her time working undercover as a hotel housekeeper, describes the hotel room for housekeepers as entering a better world - 'a world of comfort where every day is a day off, waiting to be filled with sexual intrigue' (Ehrenreich 2002: 43).

The race to the bottom for staff, relying heavily on illegal migrant labour, is concerning, as it is so readily constructed as a feature of the industry in Hotel Babylon. Increasingly though, the use of illegal migrant workers is a case of 'reality TV', as more hotels have been found to be using illegal or new 
migrant labour (Hsiao-Hung 2004). Plot lines in Hotel Babylon often illustrate what Gibson (2007) describes as the narcissistic pride in Britain's hospitality and tolerance, 'strengthened through the distinction between those genuine, deserving and grateful refugees, and those bogus, undeserving, abusive asylum seekers and economic migrants' (Gibson 2007: 163). As Charlie in Hotel Babylon says:

Below stairs it couldn't be more different. First-generation immigrants, asylum seekers and foreigners who have only a minimal grasp of English all work long hours for low wages. They have no prospect of promotion or even a whiff of a tip.

The employment conditions depicted in Hotel Babylon appear to have become undesirable to the resident population in many countries. The denigration of housekeeping staff in such a manner is puzzling and quite contrary to the important role they play in hotels internationally. A guest's satisfaction with the hotel will be considerably influenced by their impression of the room. This perception of the accommodation is particularly important as, unlike other departments where a mistake or oversight can be corrected by the server (such as a dirty glass replaced by the waiter), in the room the guest is alone and the housekeeper is not there to correct any imperfections. This suggests that the servicing of rooms is paramount in the operation of a successful hotel. The work of housekeepers is essential to comfort, hygiene and safety but 'they are almost invisible as such work is generally performed unseen and therefore anonymously' (Hunter Powell and Watson 2006: 298).

Throughout the episodes analysed, housekeepers and housekeeping are represented as being at the lowest end of the hotel hierarchy. Women often populate certain hotel jobs, not so much because they are regarded as particularly appropriate for women, but because these jobs are regarded as appropriate only for those disadvantaged in the labour force (Harris 2009). The prevailing discourse of dirty drudge work, often performed by the lowest end of the labour force (illegal migrant workers) is (re)produced through Hotel Babylon. As Baum (2007: 1396) describes:

[...] it is clear that polarisation is taking place within tourism work, but the criteria of distinction relates to the branding and image of the work rather than to its technical or professional status. 'Cool' work is equated with style, fashion and consumer branding (bars, night clubs, boutique hotels, creative venues) while 'uncool' includes the work of drudgery in the sector (cleaning, popular service).

In Hotel Babylon, the behaviour of housekeepers was also implied as 'dirty'. Constructing the staff as willing profiteers whenever possible, portrays them as opportunistic and willing to break the rules to get ahead, rather than being opportunistic in an entrepreneurial, honest way. Never as the mastermind, but rather the pawns of other staff who would bribe the housekeepers to do their 'dirty work'.

The denigration and sexualization of housekeeping work and housekeepers should also be considered from the perspective of the impression this forms on viewers, including potential labour pools and customer groups. While hotel housekeeping work is largely 'invisible', making it part of a television 
programme renders it visible. As Rivadeneyra and Ward (2005) state, television portrayals contribute directly and indirectly to shaping adolescents' notions of social reality. Although many other hotel departments portrayed appear overtly glamorized (e.g. reception, concierge), housekeeping is represented in a strikingly unpleasant manner. Hence we ask, what image of housekeeping as a career and a service is formed by viewers of Hotel Babylon? From the above analysis, we argue, it would not be a positive one, given the images of sexualization, undesirable work and powerlessness of those performing it repeatedly featured in the episodes.

No union representation is evident in Hotel Babylon, 'a fact which no doubt accurately reflects the low level of unionization in the real-life hotel sector' (Harper 2008: 120). This further exacerbates the message that housekeepers are a vulnerable group, devoid of collective strength and easily controlled by management. Further distinctions are made for potential labour pools by featuring the housekeeping workforce in Hotel Babylon as the realm of migrant labour, who receive low remuneration and variable working conditions. Such messages, even shown in a fictionalized story, can make a powerful negative impression on those forming role beliefs and making occupational choices.

\section{CONCLUSION}

Analysis of Hotel Babylon found a very interesting dialectic between the hidden/invisible work of housekeeping and the public/visible nature of television. Our analysis found an interplay of race, class, gender and sexuality in the programme, which focuses on hospitality as work/labour set in a hotel environment, glamorizing play and consumption. The content and above analysis of Series 1 of Hotel Babylon, in the wider context of the hospitality industry, suggests a more challenging set of questions. A focus on positive workplace culture, cooperation, values and great communication can improve staff retention, lowering turnover rates and enabling service quality to be maintained and bottom-line business goals to be achieved. However, a two-level system appears operating at Hotel Babylon with a western core of management and front-line staff, and another group of illegal migrant employees representing the reality of a low-pay, poorconditions, casualized industry. The concern is that this fits with the turnover issues experienced across the hospitality industry, which seems to be trapped in a downward cycle of low yield, low pay and high labour turnover (Winterton 2004).

We raise the question of how sustainable the negative employment situation, as depicted in the housekeeping department at Hotel Babylon, is and importantly, through playing out this representation through popular television, how it is further denigrating housekeeping as a career to potential labour pools in terms of the power relations, work organization, remuneration and career opportunities. In terms of hotels and hospitality generally, it relates to more fundamental concerns about sustaining service quality and employment relationships with an employment approach that appears unsustainable. 'Tourism work is a powerful issue for future tourism studies, with indisputable ethic, practical and economic and theoretical value' (Veijola 2009: 85).

Presenting hotel housekeeping as the Cinderella of hospitality underserves the work and the importance of those performing it. We finish here by 
calling for further work examining media representations of hospitality work, particularly through the medium of television as a mirror of society that is accessible by viewers across class, race, gender and ethnicity divisions.

\section{REFERENCES}

Adib, A. and Guerrier Y. (2003), 'The Interlocking of Gender with Nationality, Race, Ethnicity and Class: The Narratives of Women in Hotel Work', Gender, Work and Organisation, 10: 4, pp. 413-32.

Aitchison, C. (1999), 'New Cultural Geographies: The Spatiality of Leisure, Gender and Sexuality', Leisure Studies, 18: 1, pp. 19-39.

Ang, I. (1991), Watching Dallas: Soap Opera and the Melodramatic Imagination, London: Routledge.

Ashforth, B. and Kreiner, G. (1999), 'How Can You Do It?: Dirty Work and the Challenge of Constructing a Positive Identity', Academy of Management Review, 24: 3, pp. 413-35.

Bartley, M. (2007), “'Little Englander” - Fawlty Towers: A Textual Analysis of Nationalistic Ideology', Networking Knowledge: Journal of the MeCCSA Postgraduate Network, 1: 2. http://journalhosting.org/meccsa-pgn/index. $\mathrm{php} /$ netknow/article/viewFile/29/56. Accessed $2^{\text {nd }}$ Sept 2010.

Baum, T. (2007), 'Human Resources in Tourism: Still Waiting for Change', Tourism Management, 28: 6, pp. 1383-99.

BBC (2006), Press Packs: Hotel Babylon. http://www.bbc.co.uk/pressoffice/ pressreleases/stories/2006/01_january/11/babylon_jones.shtm. Accessed 21 December 2010.

BBC (2008), About the Show: Hotel Babylon. http://www.bbc.co.uk/drama/hotelbabylon/about_the_show_feature.shtml. Accessed 21 December 2010.

BBC Worldwide (2002), 'Allo 'Allo! http://www.bbcprograms.com/pbs/catalog/ alloallo/docs/info_alloallo.pdf. Accessed 17 Nov 2009.

Beeton, S. (2001), 'Smiling for the Camera: The Influence of Film Audiences on a Budget Tourism Destination', Tourism, Culture and Communication, 3: 1, pp. 15-25.

Bilandzic, H. (2006), 'The Perception of Distance in the Cultivation Process: A Theoretical Consideration of the Relationship Between Television Content, Processing Experience, and Perceived Distance', Communication Theory, 16: 3, pp. 333-55.

Biswas, R. and Cassell, C. (1996), 'Strategic HRM and the Gendered Division of Labour in the Hotel Industry', Personnel Review, 25: 2, pp. 19-34.

Broadcasters' Audience Research Board (BARB) (2007), http://www.barb. co.uk/index1.cfm?flag=home. Accessed 26 July 2007.

Burgoon, J. K., Birk, T. and Pfau, M. (1990), 'Nonverbal Behaviours, Persuasion, and Credibility', Human Communication Research, 17: 1, pp. 140-69.

Cabezas, A. L. (2006), 'The Eroticization of Labor in Cuba's All-Inclusive Resorts: Performing Race, Class and Gender in the New Tourist Economy', Social Identities, 12: 5, pp. 507-21.

Chartered Institute of Personnel and Development (CIPD) (2009), Recruitment, Retention and Turnover, Annual Survey Report 2009. http://www.cipd.co.uk/ default.cipd. Accessed 21 December 2010.

Common Sense Media (2008), Hotel Babylon. http://www.commonsensemedia.org/tv-reviews/Hotel-Babylon.html. Accessed 21 December 2010.

Creswell, J. W. and Miller, D. L. (2000), 'Determining Validity in Qualitative Inquiry', Theory into Practice, 39: 3, pp. 124-31. 
Darke, J. and Guerney, C. (2000), 'Putting Up? Gender, Hospitality and Performance', in C. Lashley and A. Morrison (eds), In Search of Hospitality: Theoretical Perspectives and Debates, Oxford: Butterworth-Heinemann, pp. 77-99.

Deery, M. (2002), 'Labour Turnover in International Hospitality and Tourism', in S. Watson, N. D'Annunzio-Green and G. Maxwell (eds), Human Resource Management: International Perspectives in Hospitality and Tourism, London: Continuum, pp. 51-63.

Denzin, N. K. (1970), The Research Act: A Theoretical Introduction to Sociological Methods, Chicago: Aldine.

Duncan, N. (1996), 'Sexuality in Public and Private Spaces', in N. Duncan (ed.), Bodyspace: Destabilising Geographies of Gender and Sexuality, London: Routledge, pp. 127-45.

Edwards-Jones, I. and Anon. (2004), Hotel Babylon: The Decadence and Debauchery of the Ultimate Service Industry, London: Bantam Press.

Ehrenreich, B. (2002), Nickel and Dimed: On (Not) Getting by in America, New York: Metropolitan/Owl Books.

Ehrenreich, B. and Hochschild, A. (2003), Global Woman: Nannies, Maids and Sex Workers in the New Economy, London: Granta Books.

Erpenbach, M. (2006), 'Immigration: Professional Housekeeping's Stake in the Great National Debate', Housekeeping Solutions, June. http://www. cleanlink.com/hs/article.asp?id=4666. Accessed 4 Feb 2010.

Fawltysite.net (2010), Awards and Audiences for Fawlty Towers. http://www. fawltysite.net/awards.htm. http://fawltysite.net/misc/awards.htm. Accessed 4 Feb 2010.

Frost, W. (2006), ‘Braveheart-ed Ned Kelly: Historic Films, Heritage Tourism and Destination Image', Tourism Management, 27: 2, pp. 247-54.

Gibson, S. (2007) '“Abusing Our Hospitality": Inhospitableness and the Politics of Deterrence', in J. Molz and S. Gibson, Mobilizing Hospitality: The Ethics of Social Relations in a Mobile World, Burlington, VT: Ashgate, pp. 159-74.

Guerrier, Y. and Adib, S. (2000), 'No, We Don't Provide that Service: The Harassment of Hotel Employees by Customers', Work, Employment and Society, 14: 4, pp. 689-705.

Hall, S. (1997), Representation: Cultural Representations and Signifying Practices, London: Sage.

Harper, S. (2008), "'When You Walk Through These Doors, You Can Be Anything You Want": Authenticity, fantasy and neoliberal ideology in Hotel Babylon', Journal of British Cinema and Television, 5: 1, pp. 113-31.

Harris, C. (2009), 'Building Self and Community: The Career Experiences of a Hotel Executive Housekeeper', Tourist Studies, 9: 2, pp. 144-63.

Hoffner, C. and Buchanan, M. (2005), 'Young Adults' Wishful Identification with Television Characters: The Role of Perceived Similarity and Character Attributes', Media Psychology, 7: 4, pp. 325-52.

Hoffner, C., Levine, K. and Toohey, R. (2008), 'Socialization to Work in Late Adolescence: The Role of Television and Family', Journal of Broadcasting and Electronic Media, 52: 2, pp. 282-302.

Hsiao-Hung, P. (2004), 'An Ethnography of Global Labour Migration', Feminist Review, 77: 1, pp. 129-36.

Hughes, E. C. (1971), The Sociological Eye, Chicago: Adline Atherton Inc.

Hunter Powell, P. and Watson, D. (2006), 'Service Unseen: The Hotel Room Attendant at Work', International Journal of Hospitality Management, 25: 2, pp. 297-312. 
Kinnaird, V., Kothari, U. and Hall, D. (1994), 'Tourism: Gender Perspectives', in V. Kinnard and D. Hall (eds), Tourism: A Gender Analysis, Chichester: Wiley, pp. 1-34.

Lai, P. and Baum, T. (2005), 'Just-In-Time Labour in the Hospitality Sector?', Employee Relations, 27: 1, pp. 86-102.

Lucas, R. (1995), Managing Employee Relations in the Hotel and Catering Industry, London: Cassell.

Lynch, P. A. (2005), 'Sociological Impressionism in a Hospitality Context', Annals of Tourism Research, 32: 3, pp. 527-48.

McDowell, L. (2008), 'The New Economy, Class Condescension and Caring Labour: Changing Formations of Class and Gender', NORA - Nordic Journal of Feminist and Gender Research, 16: 3, pp. 150-65.

O'Connor, N., Flanagan, S. and Gilbert, D. (2009), 'Stakeholders' Perspectives of the Impacts of Film and Television-Induced Tourism in Yorkshire', Tourism Review International, 13: 2, pp. 121-27.

Parks, L. and Kumar, S. (2003), 'Introduction', in L. Parks and S. Kumar (eds), Planet TV: A Global Television Reader, New York: New York University Press, pp. 1-18.

Pehlke, T., Hennon, C., Radina, M. and Kuvalanka, K. (2009), 'Does Father Still Know Best? An Inductive Thematic Analysis of Popular TV Sitcoms', Fathering, 7: 2, pp. 114-39.

Pritchard, A. and Morgan, N. (2006), 'Hotel Babylon? Exploring Hotels as Liminal Sites of Transition and Transgression', Tourism Management, 27: 5, pp. 762-72.

Purcell, K. (1996), 'The Relationship between Career and Job Opportunities: Women's Employment in the Hospitality Industry as a Microcosm of Women's Employment', Women in Management Review, 11: 5, pp. 17-24.

Randall, S. (2000), 'Mediated Meanings of Hospitality: Television Personality Food Programmes', in C. Lashley and A. Morrison (eds), In Search of Hospitality: Theoretical Perspectives and Debates, Oxford: ButterworthHeinemann, pp. 118-33.

Reeves, B. and Greenberg, B. S. (1977), 'Children's Perceptions of Television Characters', Human Communication Research, 3: 2, pp. 113-27.

Rivadeneyra, R. and Ward, L. M. (2005), 'From Ally McBeal to Sabado Gigante: Contributions of Television Viewing to the Gender Role Attitudes of Latino Adolescents', Journal of Adolescent Research, 20: 4, pp. 453-75.

Ryan, R. (1998), 'Managing to Compete? Employment, Work and Labour Relations in the Hospitality Industry in New Zealand', Ph.D. thesis, Victoria: University of Wellington.

Scherzer, T., Rugulies, R. and Krause, N. (2005), ‘Work-related Pain and Injury and Barriers to Workers Compensation Amongst Las Vegas Hotel Room Cleaners', American Journal of Public Health, 95: 3, pp. 483-89.

Signorielli, N. and Kahlenberg, S. (2001), 'Television's World of Work in the Nineties', Journal of Broadcasting and Electronic Media, 45: 1, pp. 4-22.

Simanoff, D. (2006), '“CSI," "Law and Order" Popularize Forensics, Criminology', Tampa Tribune (Florida), 13 February. http://www.redorbit.com/news/ technology/389342/csi_law_order_popularize_forensics_criminology/index. html. Accessed 15 December 2009.

Sinclair, T. M. (1997), Gender, Work and Tourism, London and New York: Routledge.

Statistics New Zealand (2008), 'Linked Employer-Employee Data: December 2008'. http://www.stats.govt.nz/browse_for_stats/work_ 
income_and_spending/Employment/LEED_HOTPDec08qtr.aspx. Accessed 21 December 2010.

Uriely, N. and Reichel, A. (2000), 'Working Tourists in Israel and Their Attitudes Towards Hosts', Annals of Tourism Research, 27: 2, pp. 267-84.

Veijola, S. (2009), 'Gender as Work in the Tourism Industry', Tourist Studies, 9: 2, pp. 109-26.

Veijola, S. and Valtonen, A. (2007), 'The Body in the Tourism Industry', in A. Pritchard, N. Morgan, I. Ateljevic and C. Harris (eds), Tourism and Gender: Embodiment, Sensuality and Experience, Wallingford, UK: CABI Publishing.

Warren, C. and Karner, T. (2005), Discovering Qualitative Methods: Field Research, Interviews and Analysis, Los Angeles: Roxbury.

Winterton, J. (2004), 'A Conceptual Model of Labour Turnover and Retention', Human Resource Development International, 7: 3, pp. 371-90.

Wolkowitz, C. (2006), Bodies at Work, London: Sage Publications.

Wood, R. C. (1992), Working in Hotels and Catering, London: Routledge.

— (1994), Organizational Behaviour for Hospitality Management, Oxford: Butterworth-Heinemann.

\section{SUGGESTED CITATION}

Harris, C., Tregidga, H. and Williamson, D. (2011), 'Cinderella in Babylon: the representation of housekeeping and housekeepers in the UK television series Hotel Babylon', Hospitality \& Society 1: 1, pp. 47-66, doi: 10.1386/ hosp.1.1.47_1

\section{CONTRIBUTOR DETAILS}

Dr Candice Harris is a Senior Lecturer in Management at Auckland University of Technology (AUT), Auckland, New Zealand. Her research interests include work, employment and labour market issues in hospitality, media representations of hospitality workers, gender issues in organizations and participation and well-being at work. Candice is Deputy Co-Director of the New Zealand Institute for Work and Labour Studies based at AUT.

E-mail: candice.harris@aut.ac.nz

Dr Helen Tregidga is a Senior Lecturer in Accounting at Auckland University of Technology, Auckland, New Zealand. Her research interests are primarily in the areas of business and sustainability, and social and environmental accounting and reporting and she has a particular interest in textual and discursive analysis.

E-mail: helen.tregidga@aut.ac.nz

David Williamson, Master of International Hospitality Management, First Class Honours - Auckland University of Technology

Bachelor of Arts - University of Auckland

Graduate Diploma in Business - Auckland University of Technology

Certificate in Tertiary Teaching - Auckland University of Technology

David is Senior Lecturer and Programme Leader for the Bachelor degree course of International Hospitality Management at the Auckland University of Technology. He spent eighteen years working in the hospitality industry as a bar and hotel manager and restaurateur. His research interests include 
work, employment and labour market issues in hospitality and tourism, human resource management issues in hospitality and tourism and media representations of hospitality workers. David is a member of the New Zealand Tourism Research Institute (NZTRI), and the New Zealand Work and Labour Market Institute (WaLMI) David is working on his Ph.D., a study of employment relations in the New Zealand hotel sector.

E-mail: david.williamson@aut.ac.nz

Contact: Auckland University of Technology, 42 Wakefield St, Auckland 1010, New Zealand. 